\title{
Research on a Compound Control Strategy of Three-Phase Inverter for Unbalanced Loads
}

\author{
Gaili Yue, Wen Li ${ }^{\mathrm{a}}$, Kena Li \\ College of Electrical and Control Engineering, Xi'an University of Science and Technology, Xi'an 710043, China
}

\begin{abstract}
To solve the problem of unbalanced output voltage of inverter under three-phase unbalanced load. In this paper, the main circuit topology using three-phase three-wire inverter topology. Established the mathematical model in several different coordinate system of the three-phase inverter. A compound control method is proposed by combining voltage current dual loop control method and repetitive control method, The control method is realized in three - phase $400 \mathrm{~Hz}$ inverter, and can meet the demand of unbalanced load to inverter, the reliability of the inverter circuit is improved. At the end of this paper, Matlab simulation analysis and experimental results are given, it is proved that the composite control method designed in this paper has a strong ability of unbalanced load.
\end{abstract}

\section{Introduction}

With today's power electronics technology continues to advance and rapid development in the petroleum, ship, communications switches and other fields, inverter power supply has a very wide range of applications[1]. More and more applications require three-phase inverters with very strong unbalanced load supply capability. Normally under unbalanced load conditions, three phase inverter power supply can produce unbalanced output voltage[2-3]. Thus, the three-phase inverter power supply cannot be very good normal work. Therefore, it is of great significance to improve the analysis and research of unbalanced load capacity of three-phase inverter power supply.

At present, measures for correcting output voltage asymmetry of three phase inverter under unbalanced load, the main circuit mainly includes the following topological forms: three-phase split-capacitor inversion topology[4], three-phase four-leg inverter topology[5], combined three-phase inverter topology, insertion $\Delta / \mathrm{Y}$ transformer topology[6-7]. But the four topologies have their flaws, The three phase splitting capacitance inverter topology requires a large number of DC filter capacitance, and there is a problem of the capacitor pressure, and the utilization of DC voltage will be very low[8]. The three-phase four-bridge arm contravariant topology, under the condition of adding a bridge arm, to some extent to achieve the effect of suppressing the output voltage imbalance, but also makes the control more complex, difficult to design parameters. The combined three-phase inverter topology is mainly composed of three single-phase inverters which are independent of each other. So the number of switches will be more use, increasing the difficulty of control[9]. Insert $\Delta / Y$ transformer topology structure and control methods are relatively simple. However, the weight, volume and cost of the inverter will be increased, and it is not suitable for use in high power applications [10].

The symmetrical output voltage of three phase inverter under unbalanced load is discussed in this paper, established and analyzed the mathematical model of three-phase three wire inverter. A composite control

\footnotetext{
a Corresponding author:710737995@qq.com
} 
method is proposed, mainly combined with the repeated control and double-loop control of these two control methods. The improvement of the control method is realized, and the unbalanced load capacity of the inverter is obviously improved [11]. Simulation studies show that, the inverter operates normally under various loads and can output very symmetrical voltages.

\section{Mathematical model of three-phase inverter}

As shown in Figure 1, the three phase three-wire inverter topology is composed of capacitance $\mathrm{C}$, three-phase filter inductance $\mathrm{L}$ and three-phase inverter bridge, $\mathrm{r}$ is equivalent impedance and loss. The output voltage of the inverter is $\mathrm{U}_{\mathrm{AB}}, \mathrm{U}_{\mathrm{BC}}, \mathrm{U}_{\mathrm{CA}}$, the capacitance voltage is $u_{\mathrm{ab}}, u_{\mathrm{bc}}, u_{\mathrm{ca}}$, the inductor current isi $\mathrm{A}_{\mathrm{A}}, \mathrm{i}_{\mathrm{B}}, \mathrm{i}_{\mathrm{C}}$, the load current is $i_{a}^{\prime}, i_{b}^{\prime}, i_{c}^{\prime}$.

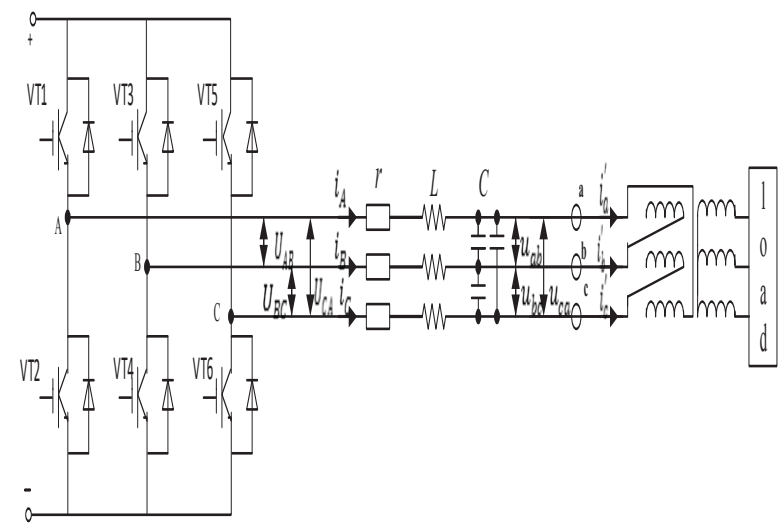

Fig. 1. Three - phase inverter main circuit topology diagram

The inductance current and capacitance voltage are treated as state quantity, can get the following equation of state:

$$
\begin{gathered}
\left\{\begin{array}{l}
3 L \frac{d i_{A}}{d t}=-u_{a b}+u_{c a}-3 r i_{A}+2 U_{A}-U_{B}-U_{C} \\
3 L \frac{d i_{B}}{d t}=-u_{b c}+u_{a b}-3 r i_{B}+2 U_{B}-U_{A}-U_{C} \\
3 L \frac{d i_{C}}{d t}=-u_{c a}+u_{b c}-3 r i_{C}+2 U_{C}-U_{A}-U_{B}
\end{array}\right. \\
\left\{\begin{array}{l}
3 C \frac{d u_{a}}{d t}=i_{A}-i_{a}^{\prime} \\
3 C \frac{d u_{b}}{d t}=i_{B}-i_{b}^{\prime} \\
3 C \frac{d u_{c}}{d t}=i_{C}-i_{c}^{\prime}
\end{array}\right.
\end{gathered}
$$

Formula 1 and Formula 2 are transformed by CLARK as follows:

$$
\begin{gathered}
\left\{\begin{array}{l}
C \frac{d u_{\alpha}}{d t}=i_{\alpha}-I_{\alpha} \\
C \frac{d u_{\beta}}{d t}=i_{\beta}-I_{\beta}
\end{array}\right. \\
\left\{\begin{array}{l}
L \frac{d i_{\alpha}}{d t}=U_{\alpha}-u_{\alpha}-r i_{\alpha} \\
d i_{\beta}
\end{array}=U_{\beta}-u_{\beta}-r i_{\beta}\right.
\end{gathered}
$$

The CLARK transform can be used to derive the mathematical model of the three-phase inverter in the stationary coordinate system, then type 3 and 4 through the Park transformation, available:

$$
\begin{gathered}
\left\{\begin{array}{l}
C \frac{d u_{d}}{d t}=\frac{1}{3} i_{d}-\frac{1}{3} I_{d}+\omega C u_{q} \\
C \frac{d u_{q}}{d t}=\frac{1}{3} i_{q}-\frac{1}{3} I_{q}-\omega C u_{d}
\end{array}\right. \\
\left\{\begin{array}{l}
L \frac{d i_{d}}{d t}=U_{d}-u_{d}-r i_{d}+\omega L_{q} \\
L \frac{d i_{q}}{d t}=U_{q}-u_{q}-r i_{q}-\omega L_{d}
\end{array}\right.
\end{gathered}
$$

The mathematical model of the three-phase inverter in the $\mathrm{dq}$ rotating coordinate system is obtained. The following vector diagram can be obtained by converting the three-phase still abc coordinate system into two phase-rotating dq coordinate systems.

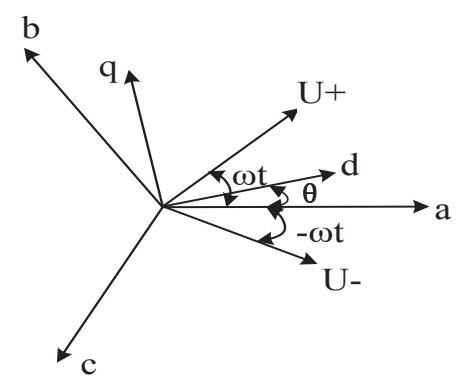

Fig. 2. abc coordinate system to $\mathrm{dq}$ coordinate system transformation

If the output voltage is set as follows:

$$
\left\{\begin{array}{c}
u_{a}=U_{m} \cos \omega t \\
u_{b}=U_{m} \cos \left(\omega t+\frac{2}{3} \pi\right) \\
u_{c}=U_{m} \cos \left(\omega t-\frac{2}{3} \pi\right)
\end{array}\right.
$$

The inverter's three-phase output voltage is converted to two-phase rotation dq coordinate system:

$$
\left[\begin{array}{l}
u_{b} \\
u_{q}
\end{array}\right]=C_{P A R K} \cdot C_{C L A R K} \cdot\left[\begin{array}{l}
u_{a} \\
u_{b} \\
u_{c}
\end{array}\right]=\left[\begin{array}{c}
U_{m} \\
0
\end{array}\right]
$$

In formula $8, C_{C L A R K}$ and $C_{P A R K}$ are CLARK transform matrices and PARK transform matrices 


$$
\begin{gathered}
C_{C L A R K}=\frac{2}{3}\left[\begin{array}{ccc}
1 & -1 / 2 & -1 / 2 \\
0 & \sqrt{3} / 2 & -\sqrt{3} / 2
\end{array}\right] \\
C_{P A R K}=\left[\begin{array}{cc}
\cos \theta & \sin \theta \\
-\sin \theta & \cos \theta
\end{array}\right]
\end{gathered}
$$

The mathematical model of the three-phase inverter can be seen from each of the above coordinate systems, in the three-phase stationary coordinate system and the $\mathrm{dq}$ rotating coordinate system, there is a coupling phenomenon between the inverters, but there is no coupling relation in alpha beta coordinate system. The inverter outputs three-phase voltage to the rotating coordinate system, the straight axis component is the phase voltage peak, the component of the cross axis is zero, thus there is only the DC component.

\section{Inverter control system design}

When the three-phase inverter is operating in a non-linear load and unbalanced load, the output voltage has periodic disturbances, and use of repetitive control methods to suppress this disturbance. And in order to improve the dynamic response of the system, a compound control algorithm with repetitive control and voltage and current double loop control is adopted. Figure 3 is a system block diagram of composite control.

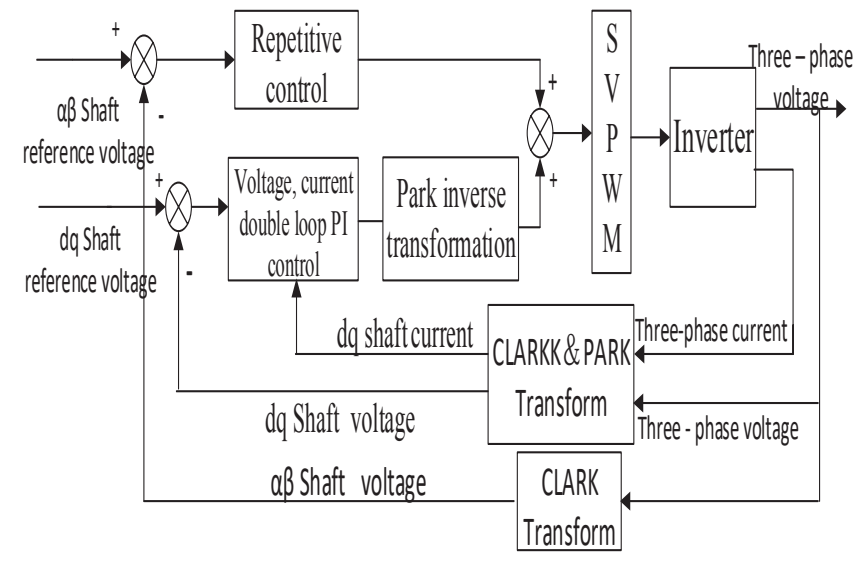

Fig. 3. Composite control system diagram

\subsection{Design of Closed - loop Controller for Voltage and Current}

The double closed-loop controller consists mainly of two parts, one part is the current inner loop controller, and the other part is the voltage outer ring controller. Among them, the current loop controller can make the inverter fast tracking the actual output current, thus, a quick response is achieved. The voltage outer ring controller can maintain stable output voltage. For the coupling of inverter, a feedforward decoupling control method is adopted to decouple voltage current. The PI regulator is used to control the current inner loop.

The current control equation is:

$$
\begin{aligned}
& u_{d}^{*}=\left(K_{P i}+\frac{K_{I i}}{\mathrm{~s}}\right)\left(i_{d}^{*}-i_{d}\right)+u_{d}-\omega L i_{q} \\
& u_{q}^{*}=\left(K_{P i}+\frac{K_{I i}}{\mathrm{~s}}\right)\left(i_{q}^{*}-i_{q}\right)+u_{q}-\omega L i_{d}
\end{aligned}
$$

The voltage control equation is:

$$
\begin{aligned}
& i_{d}^{*}=3\left(K_{P v}+\frac{K_{I v}}{\mathrm{~s}}\right)\left(u_{d}^{*}-u_{d}\right)+i_{d}^{\prime}-3 \omega C u_{q} \\
& i_{q}^{*}=3\left(K_{P v}+\frac{K_{I v}}{\mathrm{~s}}\right)\left(u_{q}^{*}-u_{q}\right)+i_{q}^{\prime}-3 \omega C u_{q}
\end{aligned}
$$

In the formula, the $K_{P i}$ is the PI regulator and the $K_{P v}$ is the integral factor of the PI regulator. The $\boldsymbol{i}_{d}^{*}$ and $\boldsymbol{i}_{q}^{*}$ are reference currents for the inner loop of the current.

Controlled by current control equation 11 and voltage control equation 12, available:

$$
\left\{\begin{array}{c}
u_{d}=\frac{1}{C S}\left[\left(K_{P v}+\frac{K_{I v}}{\mathrm{~s}}\right)\left(u_{d}^{*}-u_{d}\right)\right] \\
u_{q}=\frac{1}{C S}\left[\left(K_{P v}+\frac{K_{I v}}{\mathrm{~s}}\right)\left(u_{q}^{*}-u_{q}\right)\right] \\
i_{d}=\frac{1}{L S}\left[\left(K_{P i}+\frac{K_{I i}}{\mathrm{~s}}\right)\left(i_{d}^{*}-i_{d}\right)-r i_{d}\right] \\
i_{q}=\frac{1}{L S}\left[\left(K_{P i}+\frac{K_{I i}}{\mathrm{~s}}\right)\left(i_{q}^{*}-i_{q}\right)-r i_{q}\right]
\end{array}\right.
$$

It can be seen by equation 13 that after decoupling control, the decoupling of voltage and current is completed. Figure 4 is the block diagram of $d$ axis current closed loop control.

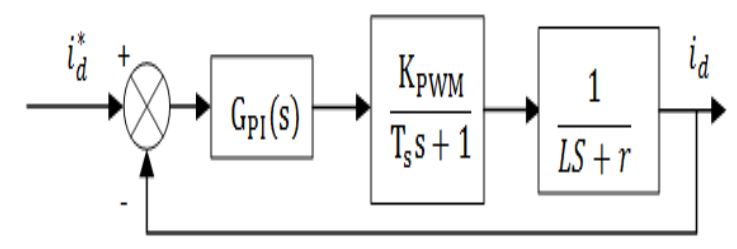

Fig. 4. D-axis current closed-loop control block diagram

In figure 4 , the $T s$ is the current sampling period (switching cycle of the inverter). The $\mathrm{L}$ is the filter inductance, the $K_{P W M}$ is the modulation ratio of the inverter, and the $\mathrm{r}$ is the equivalent impedance, the $G_{P i}$ (s) is the transfer function. 
The inverter is under the control of the current loop, in steady-state operation, $i_{q}$ is equal to zero, and the change of $i_{d}$ in dynamic process is very small. And before the big change in the DC voltage, $i_{q}$ has completed its transient process to zero, therefore. Transfer function of loop closed loop:

$$
C(s)=\frac{1}{T_{i s}+1}
$$

Formula of $T_{i s}=\mathrm{L} / K_{p i} K_{P W M}$, the voltage loop control block diagram can be drawn from the above analysis, as shown in figure 5

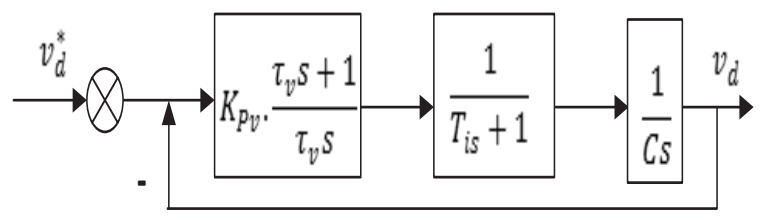

Fig. 5. Voltage loop control block diagram

It can be seen from the formula 14 that there is no coupling between the voltage and current on the dq axis, so the control block diagram of the decoupling system is as follows.

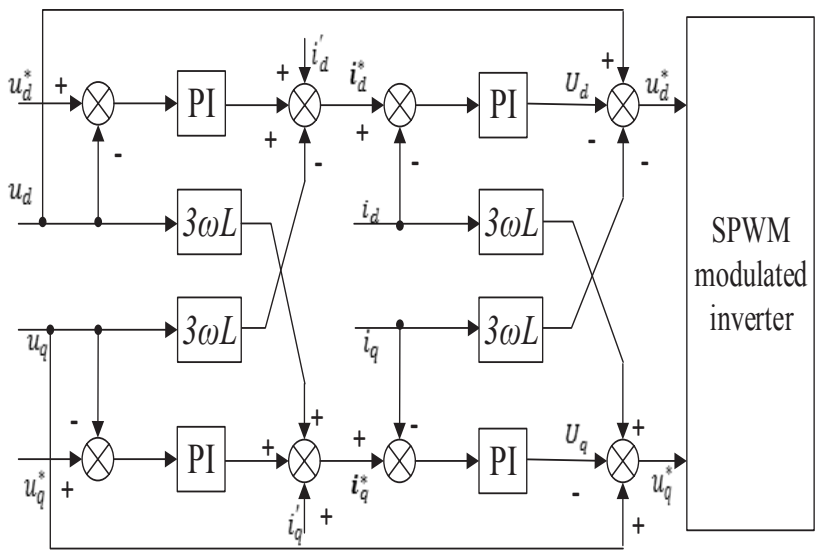

Fig. 6. Control diagram of the decoupling system

\subsection{Repetitive controller design}

Repetitive control in inverters has a wide range of applications. The main control method of the system is based on the principle of system internal mode, it is to add an "internal model" that can better describe the characteristics of the system under the control system. Therefore, the control accuracy can be improved by solving the tracking of the controlled signal.

So the core of the repetitive control system is the internal model, the performance of repetitive control lies in the establishment of internal model. Figure 7(a) is a block diagram of an ideal structure, which is equivalent to an integral of a step size with certain cycles, so that a given signal is tracked. If the repeat control system is stable, the constraint is $\|1-\mathrm{P}\| \infty<1$. However, it is difficult for the system to satisfy this constraint during the operation of the ideal internal mode. Therefore, internal model structure should be improved. As shown in Figure 7(b), in the feedback loop, the auxiliary compensator $1-z^{-N}$ is replaced by $Q(z)$ to ensure the stability of the system.

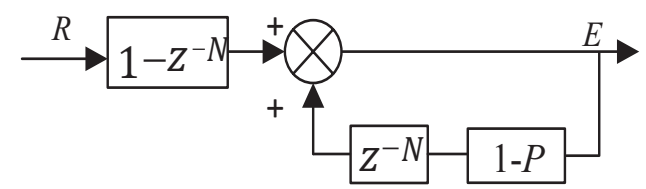

Fig. 7 (a). the ideal structure block diagram

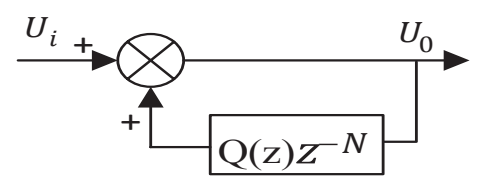

Fig. 7 (b). Improved internal model block diagram

$$
G(z)=\frac{U_{0}(z)}{E(z)}=\frac{1}{1-Q(z) z^{-N}}
$$

The $\mathrm{N}$ is the fundamental period sampling number, and the $\mathrm{Q}(\mathrm{z})$ is a low-pass filter constant, or a function, to enhance system stability, this paper takes 0.95 and $\mathrm{z}^{-\mathrm{N}}$ as the periodic delay link, the $\mathrm{E}(\mathrm{z})$ is the input and output error, the $U_{i}(\mathrm{z})$ is the internal model output.

In the improved internal model structure, the auxiliary compensator $\mathrm{S}(\mathrm{z})$ and the periodic delay link $Z^{-N}$. The complete repeat controller is constructed, as shown in figure 8.

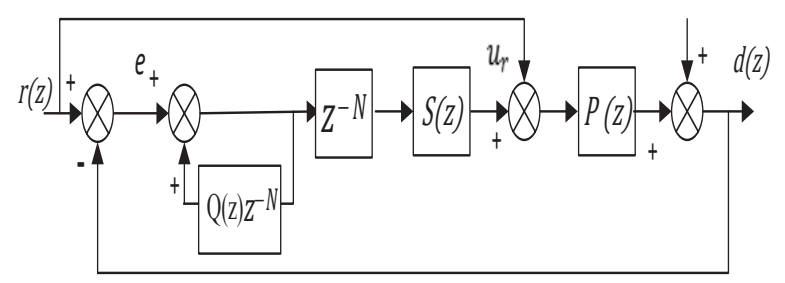

Fig. 8. Repetitive control system block diagram

The $\mathrm{P}(\mathrm{z})$ is the control object, $\mathrm{r}$ is the reference sinusoidal input signal, and $\mathrm{Z}^{-\mathrm{N}}$ is the periodic delay link, to achieve the delay control, $d$ is the interference signal. But If the object $\mathrm{P}(\mathrm{z})$ has a zero outside the unit 
circle , the compensator is $\mathrm{S}=\mathrm{P}^{-1}$ there will be a pole outside the unit circle. Therefore, the compensator is unstable at this time, resulting in instability of the repetitive control system. For this problem, the form of compensator is improved, the modified form is shown in equation 16, in advance, compensating for the phase of internal mode output signal, and then in series with a low-pass filter, this makes up a highly stable controller.

$$
S(z)=K_{r} \cdot z^{k} \cdot S^{\prime}(z)
$$

In the formula, $\mathrm{Kr}$ is the compensator gain to adjust the output amplitude, generally $0<\mathrm{Kr}<1$, the main function is to compensate filter phase, $S^{\prime}(z)$ for low pass filter, To eliminate the high resonance peak of $\mathrm{P}(\mathrm{z})$.

\section{Simulation analysis}

The three-phase inverter power supply model built in this paper is simulated on the MATLAB/Simulink simulation software. Main parameters of the system: DC input voltage $U_{i}=200 \mathrm{~V}$, filter capacitor $C_{f}=4.7 \mu \mathrm{F}, R_{f}=0.07 \Omega$, filter inductance $\mathrm{L}=11.25 \mathrm{mH}$, filter inductance internal resistance $\mathrm{R}=2 \mathrm{~m} \Omega$, rated output frequency $\mathrm{f}_{0}=400 \mathrm{HZ}$, switching frequency is $10 \mathrm{KHz}$.

Figure 9(a) is a three-phase inverter under the compound control mode, A, B, C three-phase load in which two phases for the rated load, and the output voltage simulation waveform of one phase is empty. In order to contrast, in this paper, the simulation waveforms of one phase no-load voltage in the traditional double loop control mode are shown in Figure 9(b). It is obvious that the compound control in one phase no-load of the situation does not have a big impact on the output, the balance of output voltage of inverter is obviously better and distortion is small.

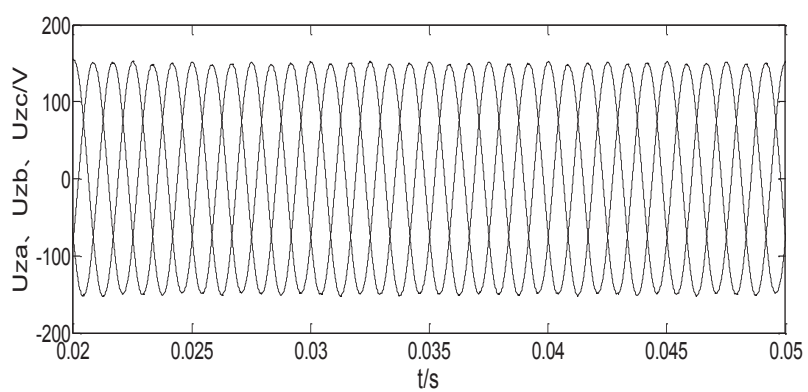

Fig. 9 (a). Voltage simulation waveforms of compound control in one phase no-load operation

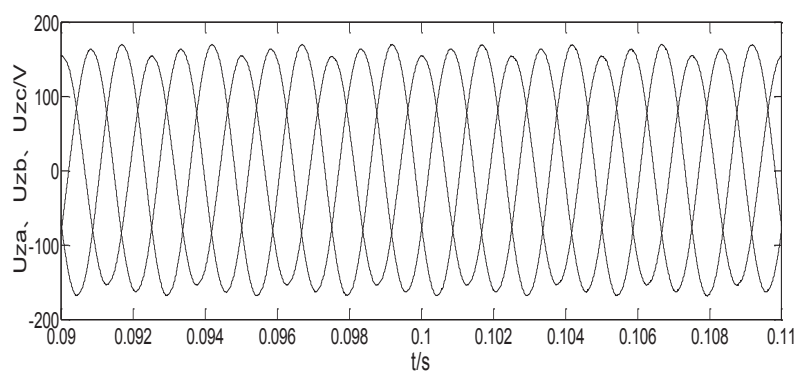

Fig. 9 (b). Double loop control voltage simulation waveform at one phase no-load operation

Figure 10 shows the case of load mutations, in the process of system two phase load operation, In $0.1 \mathrm{~s}$ when the sudden increase in one load when the composite control system and dual-loop control system voltage and current output of the simulation waveform. It is possible to see that the voltage waveform of the composite control system has not changed much before and after $0.1 \mathrm{~s}$. That is, the composite control system in the absence of one phase load still maintain the output voltage balance. The voltage output waveform under the double loop control system is shown in figure (b), there was a severe voltage imbalance before $0.1 \mathrm{~s}$, and the balance was restored after $0.1 \mathrm{~s}$. It can be seen that the output waveform of the composite control system is better.

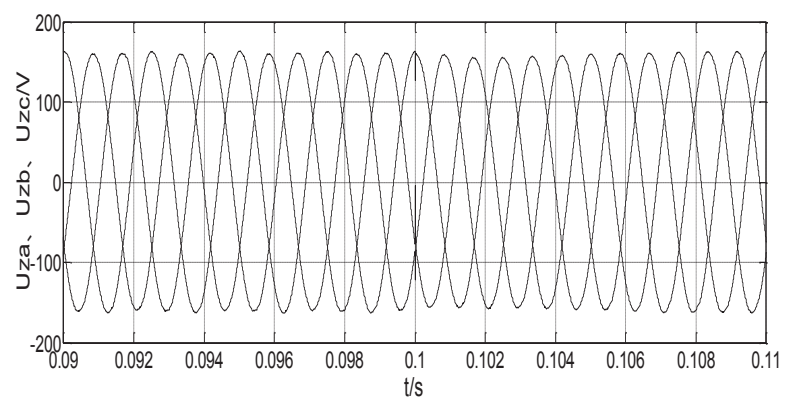

Fig. 10 (a). Composite control sudden plus one phase load voltage waveform

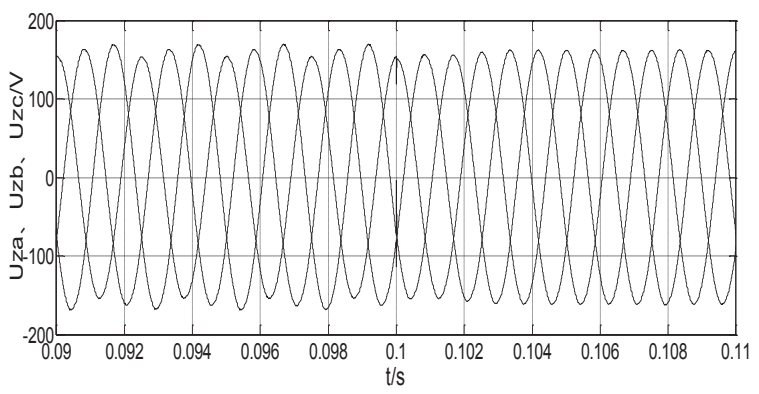

Fig. 10 (b). Double loop control sudden plus one phase load voltage waveform 


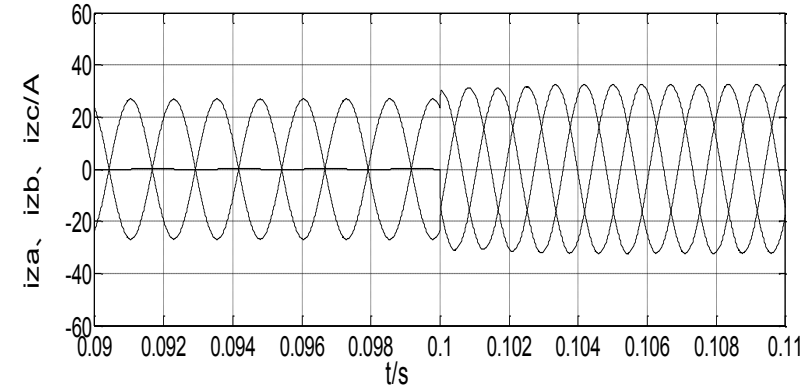

Fig. 10. (c) Compound controls sudden plus one phase load current waveform

\section{Conclusion}

In this paper, the mathematical model of three-phase three wire inverter is constructed, after analyzing and designing two kinds of inverter control methods, repetitive control and double-loop control, a composite control method combining them is proposed. And through MATLAB/Simulink simulation test verification, comparison of several simulation waveforms, it can be concluded that the dual loop control is much better than the compound control in suppressing the output voltage distortion due to unbalanced loads. The three-phase $400 \mathrm{~Hz}$ inverter can maintain the voltage balance better under the compound control. And the system has fast response speed, easy to control and fast response, and the structure of the control method is relatively simple.

\section{Reference}

1. Li Cui. Control system analysis of single phase $400 \mathrm{~Hz}$ inverter power supply [D]. Wuhan: Wuhan University of Science and Technology, 2015.

2. SUN Chi, MA Weiming, LU Junyong. Analysis of the unsymmet-rical output voltages distortion mechanism of three-phase inverterand its correction [J] Proceedings of the CSEE, 2006, 26 ( 21 ):57 -64 .

3. Cao Taiqiang, Qi Qiang, Wang Jun. Study on unbalanced load of three-phase inverter[J]. Electric Machines and Control, 2012, 16(4): 50-55(in Chinese).

4. Jeong C Y, Cho J G, Kang Y, et al. A 100k VA power conditioner for three-phase four-wire emergency generators[C]. IEEE PESC'98, Fukuoka, Japan, 1998.
5. Sun Chi, Lu Junyong, Ma Weiming. A novel control method forthree-phase Four-leg Invert [J]. Transaction of China Electrotechnical So-ciety, 200722 (2) : 57-63.

6. Uffe Borup Jensen, Prasad N Enjeti, Frede Blaabjerg. A new space vector based control method for ups systems powering nonlinear and unbalanced loads[J]. IEEE Trans on IA. 2001, 37(6): 1864-1870.

7. Kong Xuejuan, Wang Jingjiang. Waveform Control Technology of Three - phase Voltage Source Inverter Based on Internal Model Principle [J] Chinese Journal of Electrical Engineering, 2003, 23(7):67-70.

8. Kukrer O, Komurcugil H, Doganalp A. A three-level hysteresis function approach to the sliding-mode control of single-phase UPS inverters $[\mathrm{J}]$. IEEE Trans on Industrial Electronics, 2009, 56(9): 3477-3486.

9. Chen Daolian, Li Xun, Zhang Rong. Research on Combined Three - phase High Frequency Pulse DC Link Inverter $[\mathrm{J}]$. Chinese Journal of Electrical Engineering, 2005, 25(8): 75-79.

10. Ilavarasi V, Rajan C C A. quality improvement in grid connected system using four leg VSI[C]//Advances in Engineering, Science and Management. Tamil Nadu, India: ICAESM, 2012: 540-546.

11. Zheng Zhiyao, Sun Qinpei, Wang Jiangbo. Synchronous control method of combined three phase inverter $[\mathrm{J}]$. Journal of Agricultural Engineering, 2015, 31 (5): 146-151. 